\title{
Research on Creep Characteristics and Influencing Factors of Cement Asphalt Composite Binder
}

\author{
Yimin Li, ${ }^{1}$ Mulbah Yombah, ${ }^{2}$ Ahmed Abdulakeem Temitope, ${ }^{2}$ Xiaolong Zou, ${ }^{2}$ \\ Fayong Yang $\mathbb{D}^{2},{ }^{2}$ Wenbo $\mathrm{Li}^{2}$, and Hongjun Jing $\mathbb{D}^{2}$ \\ ${ }^{1}$ Ankang City Traffic Construction Quality Supervision Station of Shaanxi Province, Ankang 725000, China \\ ${ }^{2}$ School of Architecture and Civil Engineering, Xi'an University of Science and Technology, Xi'an 710064, China \\ Correspondence should be addressed to Hongjun Jing; jinghongjun@xust.edu.cn
}

Received 25 October 2020; Revised 10 December 2020; Accepted 19 December 2020; Published 29 December 2020

Academic Editor: Bowen Guan

Copyright (c) 2020 Yimin Li et al. This is an open access article distributed under the Creative Commons Attribution License, which permits unrestricted use, distribution, and reproduction in any medium, provided the original work is properly cited.

Cement emulsified asphalt composite material (CA composite cement) has the excellent properties of cement and emulsified asphalt cement. As a composite cementing material, cement emulsified asphalt concrete can be one of the choices of road paving materials. However, under the effect of temperature and wheel load, the performance of it may get worse; especially, the creep behavior of CA composite cement has an important influence on the stability of pavement structure. This paper mainly focuses on the research on the creep and creep recovery performance of CA composite cement, determines the raw materials and proportions of CA composite cement, and formulates experimental research programs such as creep and creep recovery tests and stress scanning tests. The creep and creep recovery test research of CA composite cement was carried out, and the influence of creep and creep recovery characteristics, temperature, and A/C on the creep mechanical properties of CA composite cement was analyzed. The results show that the creep compliance of CA composite cement decreases with the increase of aging degree, the static mechanical properties tend to be elastic as a whole, and different factors such as temperature and $\mathrm{A} / \mathrm{C}$ have different effects on the viscoelastic-plastic mechanical properties of the material.

\section{Introduction}

Cement emulsified asphalt concrete is a road paving material formed by using cement and emulsified asphalt as a cementing material, and together with suitable grading aggregates through cold mixing, cold laying, and rolling. Obviously, cement emulsified asphalt concrete has achieved the goal of significantly reducing energy consumption and pollutant emissions in the production and construction process. At the same time, it uses the characteristics of the emulsified asphalt in the material system to release water during demulsification and the water requirement during cement hydration to promote the strength development of composite materials, which will absorb the flexibility of asphalt concrete and the rigid characteristics of cement concrete, and has outstanding advantages such as energysaving and emission reduction, complementary performance, and strong constructability [1-7]. As a cementing material, cement emulsified asphalt composite material does not have similar normative indicators such as penetration, ductility, and softening point to evaluate its performance. Therefore, there is a lack of appropriate method indicators when preparing cement emulsified asphalt composite materials to characterize and judge the rationality of its material composition [8-13]. When the composition ratio of cement and emulsified asphalt changes within a certain range, the cement emulsified asphalt composite material behaves as a viscoelastic material, especially with different material compositions and different ages, and the viscoelastic properties of the composite material have obvious changes [14-16].

Ji [17] determined the various index parameters, initial mix ratio, and construction mix ratio of CA mortar filling layer through the research and analysis of the raw material selection principle of CA mortar raw materials. From the perspective of construction technology and material 
selection, some performance suggestions have been improved. Song et al. [18] studied the characteristics of the durability, stability, and mechanical properties of CA mortar based on the typical material selection and material ratio of CA mortar, analyzed its main influencing factors, and described the structure formation and the microlevel evolution mechanism provides technical support for the operation and maintenance of the CA mortar layer of the slab ballastless track. Fu et al. [19] presented the results of observations of scanning electron microscope micro/macrocrack development and simultaneous measurements of temperature-dependent stress-strain relations of hardened cement pastes and mortar under a steady thermal state and a displacementcontrolled loading process. Lucas et al. [20] and others comprehensively analyzed the damage development process and mechanism of asphalt mixture, combined with the principle of viscoelasticity, established the damage model of asphalt mixture, and obtained the model parameters by fitting the results of the uniaxial creep test. Saber et al. [21] analyzed and studied various creep damage development rules and their mechanisms and clarified the way of creep damage development and changes from a microscopic point of view and the basic rules of changes over time. $\mathrm{Xu}$ and Wang [22] put forward a digital simulation modeling and test method for viscoelastic mechanical properties of CA mortar by comparing the results of the creep test and digital simulation experiment of CA mortar.

At present, the research on the creep performance and creep damage development law of CA composite cement has achieved certain results and has laid a solid foundation for the study of the viscoelastic mechanical behavior of the material. However, the different influence on viscoelastic plastic has not been studied systemically. This article mainly studies the creep and recovery characteristics of CA composite cement, analyzes the influence of aging on its creep performance, discusses the influence of different factors such as temperature and $\mathrm{A} / \mathrm{C}$ on its viscoelastic mechanical properties, and will further supplement the cement research on related fields of asphalt composite cement.

\section{Materials and Methods}

\subsection{Materials}

2.1.1. Cement and Emulsified Asphalt. The cement used in this paper is Portland Ordinary Cement No. 42.5 produced by Baoji, Shaanxi. The properties of the cement were tested in accordance with JTG E30-2005, and the results are shown in Table 1. The emulsified bitumen must be cationic emulsified bitumen, and the demulsification speed should not be too fast to facilitate the full mixing of the internal components; that is, the emulsified bitumen with slow cracking or medium cracking should be selected. The properties of slow-cracking emulsified asphalt are shown in Table 2. In order to reduce the difficulty of mixing and comprehensively consider the requirements of the mix ratio [23], additional water is needed to control the water-cement ratio during the material mixing process, and the watercement ratio is determined to be 0.8 .
2.1.2. Additives. The additives used in CA composite cement mainly include defoamers, water reducers, and thickeners. Due to the cement hydration process and mixing process, it is easy to produce more air bubbles in the mixed fluid. If it cannot be discharged in time, the molded test piece will have a larger porosity, which will affect the various mechanical properties of the test piece. It will have a greater impact [24]. The purpose of adding defoamers is to reduce the content of bubbles during the molding process of the specimen. The basic properties of defoamers are shown in Table 3. In order to ensure that the CA composite cement has a certain viscosity during mixing and avoid material segregation, a thickener needs to be added to increase the viscosity. The thickener is diluted to 25 times with water at a ratio of $1: 24$ during use. The basic properties of the thickener are shown in Table 4. The main purpose of the water reducing agent is to reduce water consumption while ensuring the fluidity and workability of the cement. It can reduce the water-cement ratio to a certain extent and improve the bonding performance of the CA composite cement. The basic properties of water reducing agent are shown in Table 5.

\subsection{Material Mix Design and Ultraviolet Aging Test}

2.2.1. Mix Design. In order to study the effect of material ratio on the mechanical properties of CA composite cement, the material ratio of CA composite cement was determined as shown in Table 6. The water content of the emulsified asphalt in the mixing ratio design in the table is $45 \%$. When the mass ratio of different asphalt to cement is changed, the ratio of the water-cement ratio was controlled to be $1: 0.8$.

2.2.2. Ultraviolet (UV) Aging Test. The UV aging test was carried out in an ultraviolet aging box. After the actual measurement, the ultraviolet radiation intensity on the surface of the specimen under the stable working state of the aging box was $13.85 \mathrm{~mW} / \mathrm{cm}^{2}$. The aging time of this study was $12 \mathrm{~h}$.

2.3. Creep and Creep Recovery Test Plan. The dynamic shear rheometer (DSR) shown in Figure 1 was used to carry out the mechanical performance test of CA composite cement, including the creep and creep recovery test [25]. Based on the existing theoretical results, when the complex modulus of the specimen changes from $100 \%$ to $90 \%$ during the stress scanning process, the materials were all within the online viscoelastic range. The scanning stress range was set from $100 \mathrm{~Pa}$ to $1,200,000 \mathrm{~Pa}$, and the stress scanning test was performed on the CA composite cement specimens with different mix ratios. Use the vernier caliper to measure the length, width, and thickness of the test piece, input the size parameters, then fix the test piece on the fixture, and use the dynamic rheological shear instrument to carry out the stress scanning test. During the test, the change of the complex modulus was observed in real time. 
TABLE 1: Basic properties of cement.

\begin{tabular}{lcccc}
\hline Specific surface area $\left(\mathrm{m}^{2} / \mathrm{kg}\right)$ & Initial setting time $(\mathrm{min})$ & Final setting time $(\mathrm{min})$ & 3D intensity $(\mathrm{MPa})$ & Ignition loss $(\%)$ \\
\hline 300 & 50 & 560 & 17 & 5 \\
\hline
\end{tabular}

TABLE 2: Basic properties of emulsified asphalt.

\begin{tabular}{lccccc}
\hline \multirow{2}{*}{ Cement adaptibility } & \multicolumn{3}{c}{ Evaporation residue } & & \multirow{2}{*}{ Demulsification speed } \\
& Content $(\%)$ & Penetration $\left(25^{\circ} \mathrm{C}, 0.01 \mathrm{~mm}\right)$ & Ductility $(\mathrm{cm})$ & Softening point $\left({ }^{\circ} \mathrm{C}\right)$ & Slow cracking \\
\hline Qualified & 54 & 70 & 125 & 47 & S \\
\hline
\end{tabular}

TABle 3: Basic properties of defoamers.

\begin{tabular}{lcccc}
\hline Type of defoamers & Active ingredients (\%) & $\mathrm{pH}$ value & Valid period (d) & Stability \\
\hline Silicone defoamers & $11 \pm 3$ & $6.5 \sim 7.5$ & 360 & No stratification \\
\hline
\end{tabular}

TABLE 4: Basic properties of thickener.

\begin{tabular}{lccccc}
\hline Variety & Thickening performance & Durability & Solid content (\%) & pH & Viscosity (MPa·s) \\
\hline Cylin & Excellent & Good & 30 & 3.5 & 42 \\
\hline
\end{tabular}

TABLE 5: Basic properties of water reducing agent.

\begin{tabular}{lccccc}
\hline Density $\left(\mathrm{g} / \mathrm{cm}^{3}\right)$ & $\mathrm{pH}$ & Solid content $(\%)$ & Sodium sulfate content $(\%)$ & Chloride $(\%)$ & Total alkali $(\%)$ \\
\hline 1.07 & 8.8 & 21.32 & 0.93 & 0 & 1.3 \\
\hline
\end{tabular}

TABle 6: Material ratio.

\begin{tabular}{lcccccc}
\hline Mix ratio & Cement & Asphalt & Water & Water reducing agent & Thickener & Defoamers \\
\hline 0.3 & 1.0 & 0.3 & 0.548 & 0.015 & 0.075 & 0.003 \\
0.6 & 1.0 & 0.6 & 0.458 & 0.015 & 0.075 \\
0.9 & 1.0 & 0.9 & 0.368 & 0.015 & 0.075 \\
1.2 & 1.0 & 1.2 & 0.278 & 0.015 & 0.075 \\
1.5 & 1.0 & 1.5 & 0.188 & 0.015 & 0.075 \\
\hline
\end{tabular}

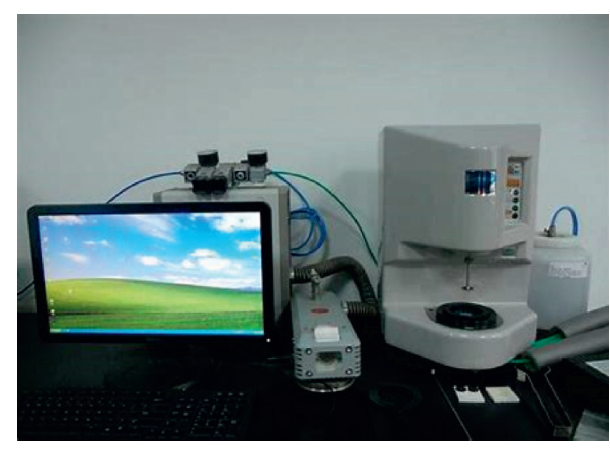

FIgure 1: Dynamic shear rheometer.

2.4. Stress Scanning Analysis. In order to analyze the influence of stress level on the creep and creep recovery performance of CA composite cement, six different stress levels were selected. The stress levels are different. During the creep test, CA composite cement will produce different degrees of creep. The damage will affect its creep behavior and creep recovery behavior. To this end, it is necessary to conduct a stress scanning test in advance to determine the creep stress corresponding to different stress levels. During the stress scanning process, the complex modulus of the material decreases as the scanning stress increases. When the complex modulus decreases not more than $10 \%$ of the initial value, the material properties are considered to be within the linear viscoelastic range. The stress levels are, respectively, selected from the benchmark of $50 \%, 100 \%$, and $150 \%$, and $200 \%$ used as creep loads in this paper, and the test temperatures were $30^{\circ} \mathrm{C}, 45^{\circ} \mathrm{C}$, and $60^{\circ} \mathrm{C}$, respectively. The stress scanning test obtains the corresponding stress when the complex modulus drops to $90 \%$ of the initial value, and then the creep stress corresponding to different stress levels can be obtained. The creep load is shown in Table 7 .

\section{Results and Discussion}

3.1. Creep and Creep Recovery Characteristics of CA Composite Cement. According to the aforementioned CA composite cement's creep and creep recovery test plan, creep and creep recovery tests at different temperatures and different stress levels were conducted. According to the test results, the creep and creep recovery compliances are shown in Figures 2-6. 
TABLE 7: Creep stress table.

\begin{tabular}{|c|c|c|c|c|c|}
\hline \multirow{2}{*}{$\mathrm{A} / \mathrm{C}$} & \multirow{2}{*}{ Temperature $\left({ }^{\circ} \mathrm{C}\right)$} & \multicolumn{4}{|c|}{ Stress level (\%) } \\
\hline & & 50 & 100 & 150 & 200 \\
\hline \multirow{3}{*}{0.3} & 30 & 0.15 & 0.30 & 0.45 & 0.60 \\
\hline & 45 & 0.07 & 0.14 & 0.21 & 0.28 \\
\hline & 60 & 0.05 & 0.09 & 0.14 & 0.18 \\
\hline \multirow{3}{*}{0.6} & 30 & 0.14 & 0.27 & 0.41 & 0.54 \\
\hline & 45 & 0.09 & 0.18 & 0.27 & 0.36 \\
\hline & 60 & 0.04 & 0.07 & 0.11 & 0.14 \\
\hline \multirow{3}{*}{0.9} & 30 & 0.10 & 0.20 & 0.30 & 0.40 \\
\hline & 45 & 0.05 & 0.10 & 0.15 & 0.20 \\
\hline & 60 & 0.09 & 0.17 & 0.26 & 0.34 \\
\hline \multirow{3}{*}{1.2} & 30 & 0.09 & 0.17 & 0.26 & 0.34 \\
\hline & 45 & 0.03 & 0.06 & 0.09 & 0.12 \\
\hline & 60 & 0.02 & 0.03 & 0.05 & 0.06 \\
\hline \multirow{3}{*}{1.5} & 30 & 0.08 & 0.16 & 0.24 & 0.32 \\
\hline & 45 & 0.03 & 0.06 & 0.09 & 0.12 \\
\hline & 60 & 0.01 & 0.02 & 0.03 & 0.04 \\
\hline
\end{tabular}

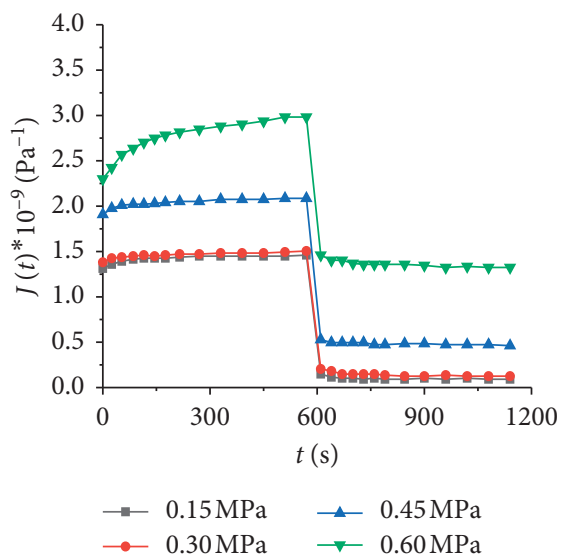

(a)

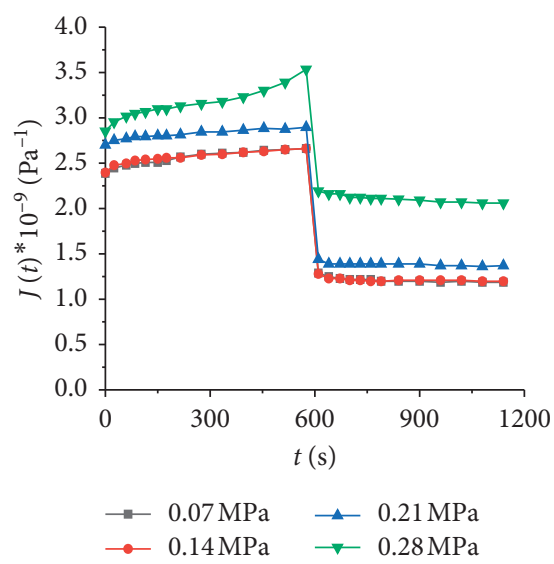

(b)

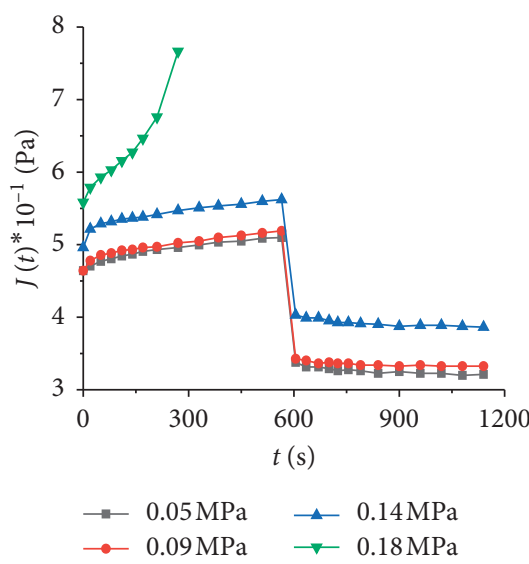

(c)

FIgURE 2: A/C $=0.3$ creep and creep recovery compliance curve. (a) $30^{\circ} \mathrm{C}$. (b) $45^{\circ} \mathrm{C}$. (c) $60^{\circ} \mathrm{C}$.

It can be seen from Figures $2-6$ that at the moment $t=0$, that is, the moment of stress loading, the CA composite cement will produce instantaneous deformation, and the magnitude of instantaneous deformation closely related to the stress level. As the stress level increases, the instantaneous deformation also increases. This part of the instantaneous deformation includes instantaneous elastic deformation and instantaneous plastic deformation. As the stress level increases, when the stress exceeds a certain value, plastic deformation will occur instantaneously at the moment of loading, and this part of the deformation cannot be recovered. After instantaneous deformation occurs at the moment of loading, it then enters the deceleration creep stage. In this stage, the creep rate gradually decreases and then enters the constant velocity creep stage. In the constant velocity creep stage, the compliance rate is basically constant. For CA composite cement with different proportions, the creep stress has a significant effect on its creep behavior. When the creep stress is small, in the 600s creep time, the creep curve only includes two stages of deceleration creep and constant velocity creep. When the creep stress is large, as the creep stress increases, the creep rate in the deceleration and constant velocity phases increases, and it quickly enters the accelerated creep phase. In some cases, due to the creep in the accelerated creep phase, the rate of change is relatively large, and the creep damage occurs within $t=600 \mathrm{~s}$, but the subsequent creep recovery phase is not entered. From the comparison of the curves of the creep recovery stage after $t=600 \mathrm{~s}$, it can be seen that with the increase of the creep stress, the creep recovery compliance increases, and with the increase of the creep stress, the deformation recovery ability of the CA composite adhesive decreases. The residual strain of the material increases.

It can also be seen from the figure that the creep compliance and creep recovery compliance of CA composite cement basically coincide under low-stress levels, which is in line with the physical characteristics of creep compliance and creep recovery compliance. Within the range of online viscoelasticity, creep compliance and creep recovery compliance as the basic material parameters of viscoelastic materials have nothing to do with the stress level. Creep compliance and creep recovery compliance are determined by the nature of 


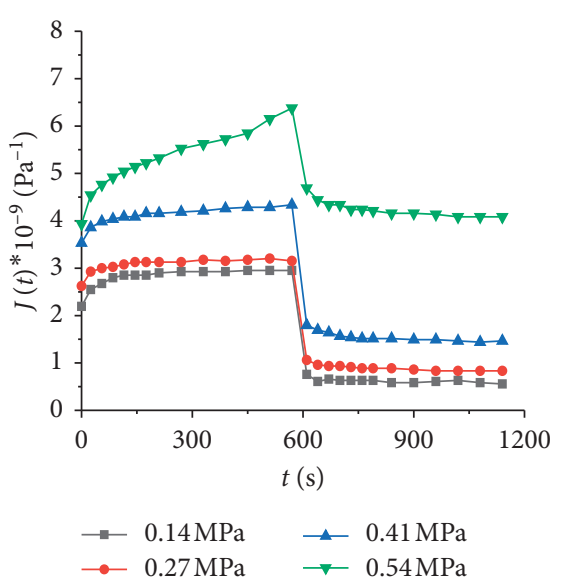

(a)

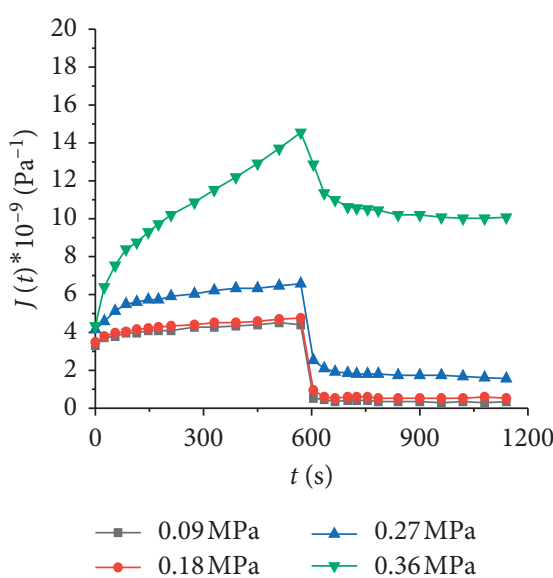

(b)

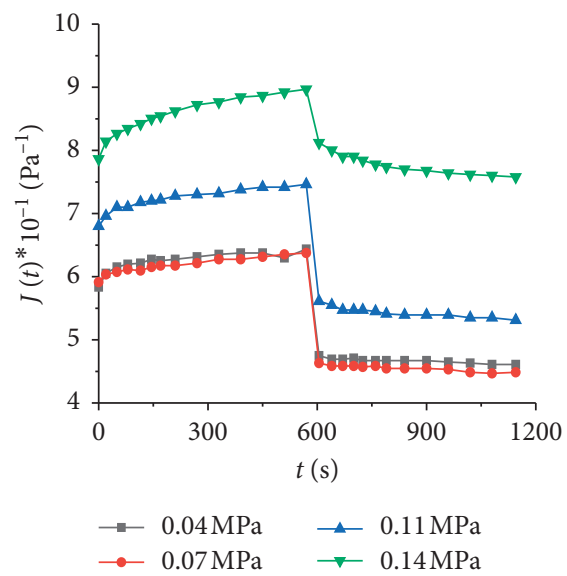

(c)

Figure 3: A/C $=0.6$ creep and creep recovery compliance curve. (a) $30^{\circ} \mathrm{C}$. (b) $45^{\circ} \mathrm{C}$. (c) $60^{\circ} \mathrm{C}$.

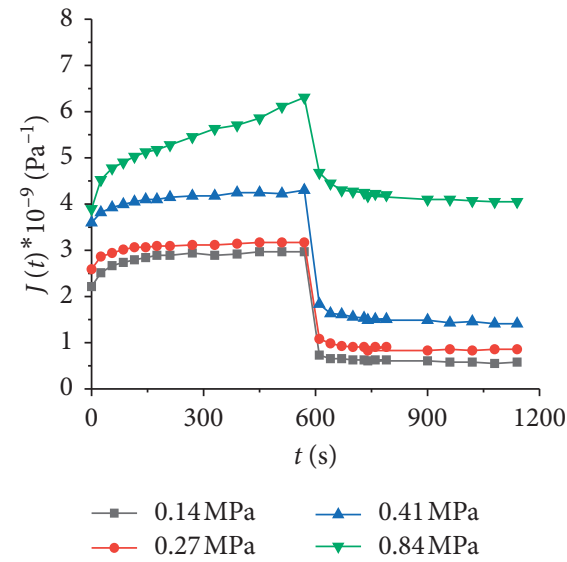

(a)

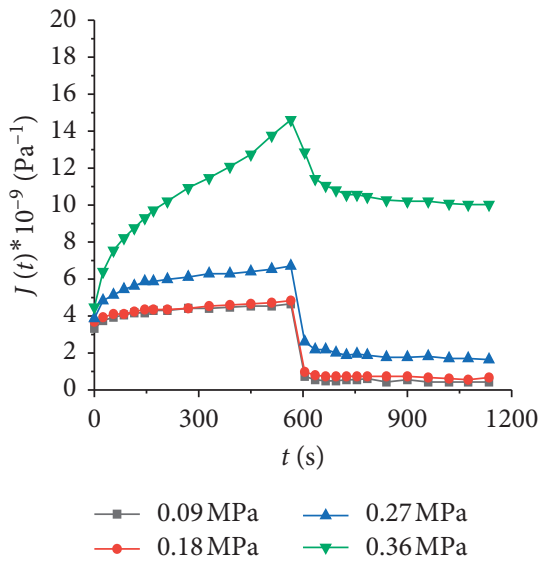

(b)

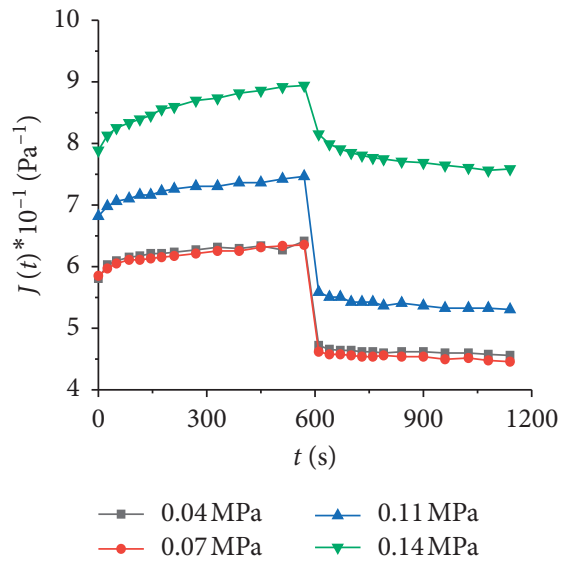

(c)

Figure 4: $\mathrm{A} / \mathrm{C}=0.9$ creep and creep recovery compliance curve. (a) $30^{\circ} \mathrm{C}$. (b) $45^{\circ} \mathrm{C}$. (c) $60^{\circ} \mathrm{C}$.

the material itself and its external loads. However, under the condition of high-stress level, during the creep test process, the material has large creep damage, which causes the creep deformation of the material to increase, so its creep and creep recovery compliance increase accordingly.
3.2. Effect of Aging on Creep Properties of CA Binder. The indoor ultraviolet accelerated aging test is used to simulate the aging of cement asphalt composite material in the actual use environment. The aging time is $150 \mathrm{~h}, 300 \mathrm{~h}, 600 \mathrm{~h}$, and $900 \mathrm{~h}$ and the test results are shown in Figure 7. It can be seen 


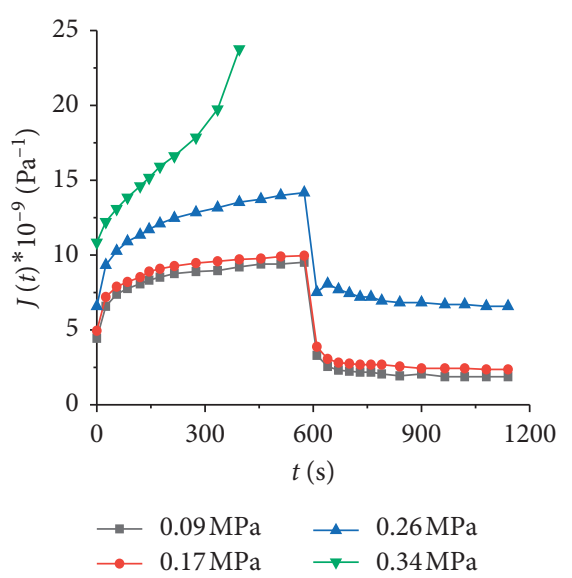

(a)

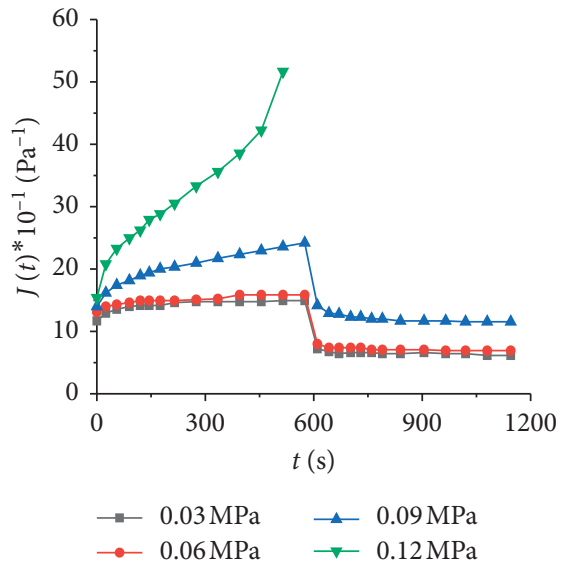

(b)

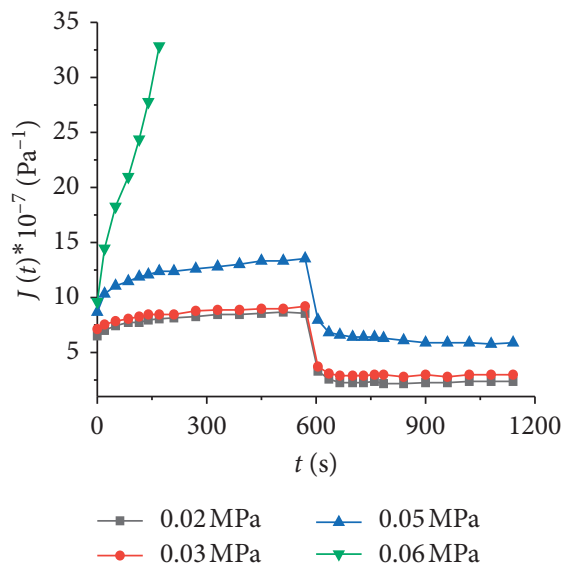

(c)

Figure 5: A/C $=1.2$ creep and creep recovery compliance curve. (a) $30^{\circ} \mathrm{C}$. (b) $45^{\circ} \mathrm{C}$. (c) $60^{\circ} \mathrm{C}$.

from Figure 7 that, as the degree of aging increases, the creep compliance of the CA cement with the same raw material ratio in the creep recovery phase and the absolute value of the incremental compliance increase in the deceleration recovery phase decrease, while the creep compliance of the gap between the curves gradually stabilizes as the recovery time increases. The above shows that the instantaneous elasticity, delayed elasticity, and viscous flow deformability of CA cement all weaken as the degree of aging increases, which is the same as the conclusion obtained from the creep test. As the degree of aging deepens, the deceleration creep and deceleration recovery phases of the CA cement are gradually shortened. When the aging time is $900 \mathrm{~h}$, the deceleration creep and deceleration recovery phases of the CA cement of each ratio tend to disappear. As the degree deepens, the CA cement will gradually change from viscoelastic body to elastomer and tend to be hard and brittle.

In the initial period of aging, the asphalt component in CA binder is rapidly oxidized by UV, and the light component in the system decreases rapidly, which leads to the rapid decline of the flexibility and deformation ability of the material. With the aging process, the active light components easy to react in asphalt decrease, and the aging speed of asphalt slows down, which results in the change of viscoelastic deformation capacity of the material. When the aging time is long enough, the creep deformation capacity of CA binder will tend to be stable and will not change with the aging time.

3.3. Influence of Temperature on Viscoelastic-Plastic Mechanical Properties. The changes of $J_{K}(600) / J(600), J_{K}$ $(600) / J_{H}(600)$, and $J_{1}(600) / J(0)$ with temperature are shown in Figures $7-11$. From the subfigure (a) in Figures $8-12$, it can be seen that, under the same stress level conditions, $J_{K}(600) / J(600)$ increases with increasing temperature; that is, the ratio of viscoplastic strain to total strain increases, indicating that the temperature increases and the viscoplastic deformation of CA composite cement increases. It can be seen from subfigure (b) in Figures 8-12 that, under the same stress level conditions, $J_{K}(600) / J_{H}$ (600) increases with increasing temperature; that is, the ratio of plastic strain to recoverable strain gradually increases to large, indicating that the temperature rises and the proportion of residual deformation gradually increases; from subfigure (c), it can be seen that, under the same stress level, $J_{1}(600) / J(0)$ decreases with the increase of temperature. That is, the ratio of elastic strain to elastic-plastic 


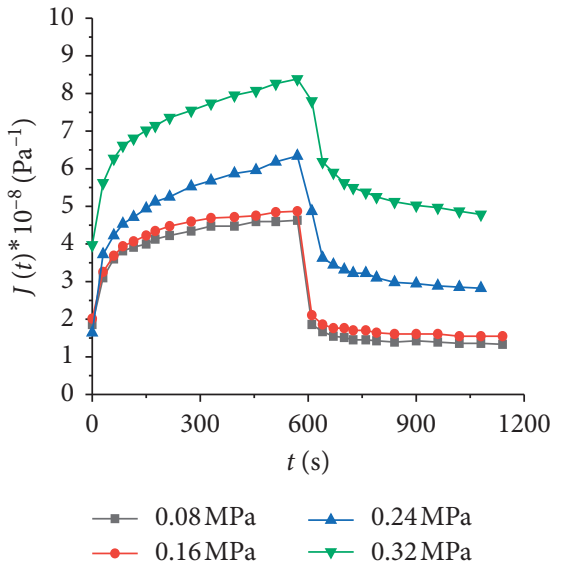

(a)

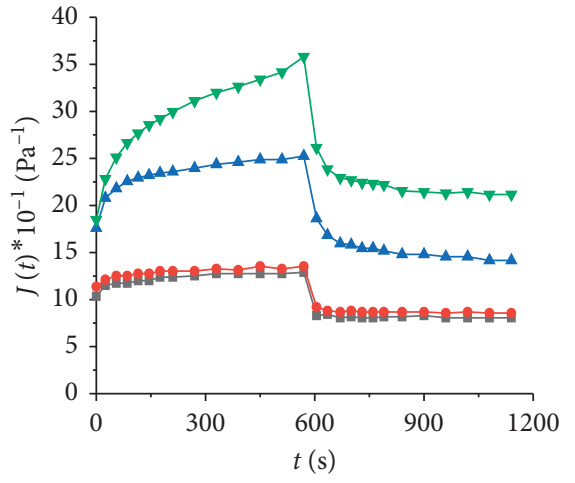

$\rightarrow 0.03 \mathrm{MPa} \longrightarrow 0.09 \mathrm{MPa}$

$\rightarrow 0.06 \mathrm{MPa} \rightarrow 0.12 \mathrm{MPa}$

(b)

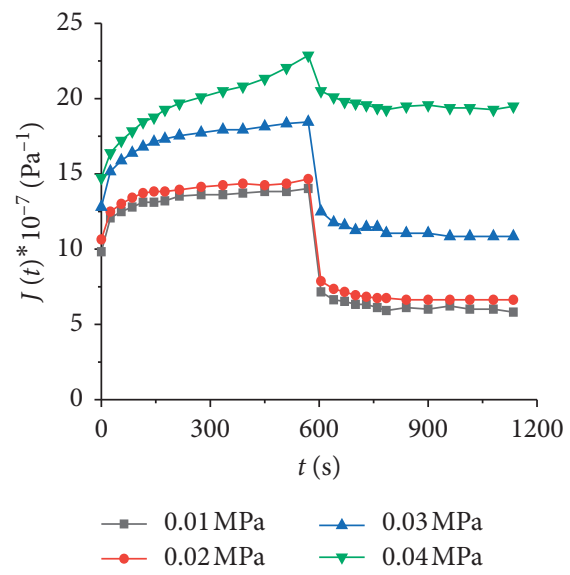

(c)

Figure 6: $\mathrm{A} / \mathrm{C}=1.5$ creep and creep recovery compliance curve. (a) $30^{\circ} \mathrm{C}$. (b) $45^{\circ} \mathrm{C}$. (c) $60^{\circ} \mathrm{C}$.

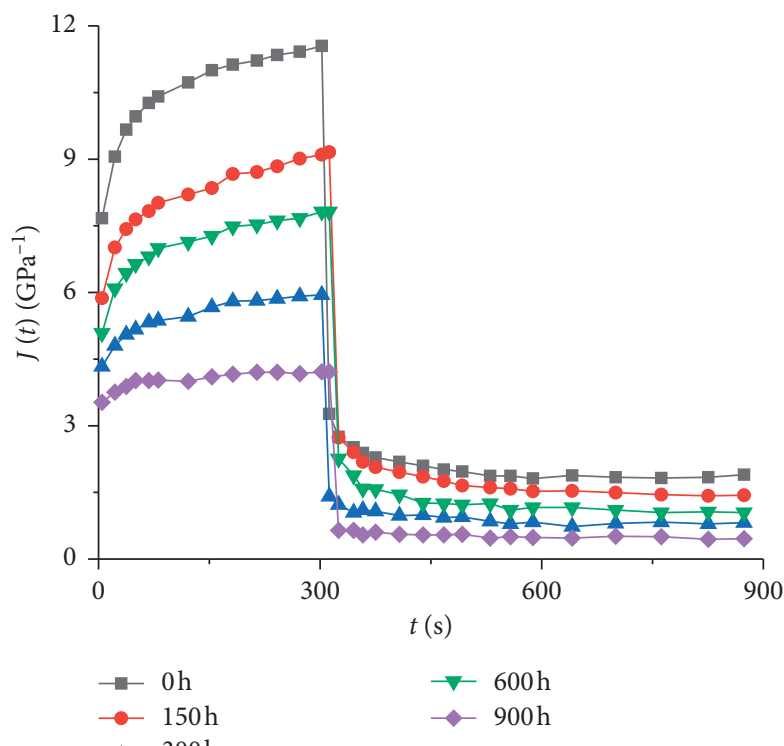

(a)

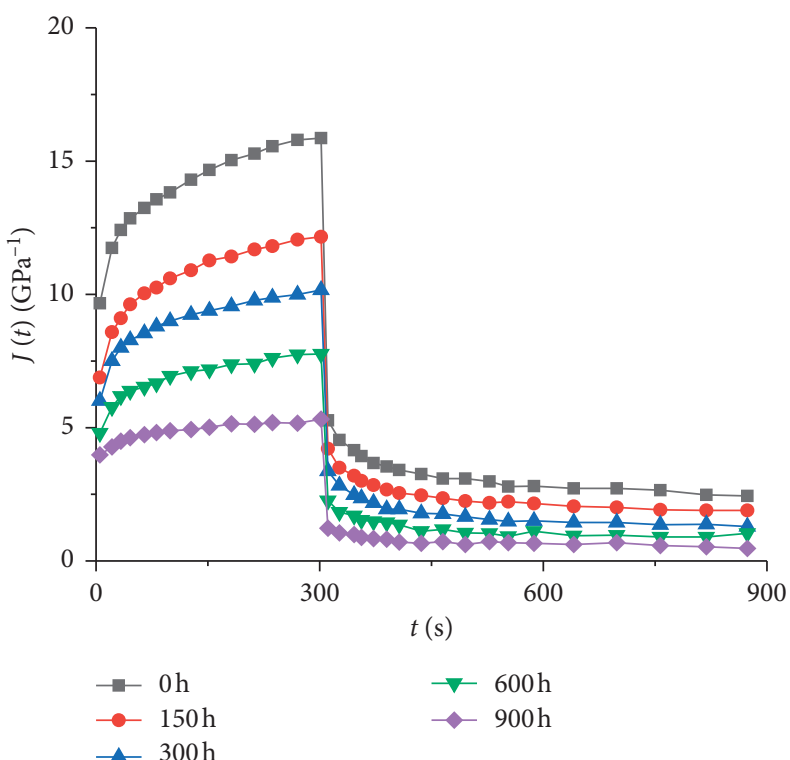

(b)

Figure 7: Continued. 


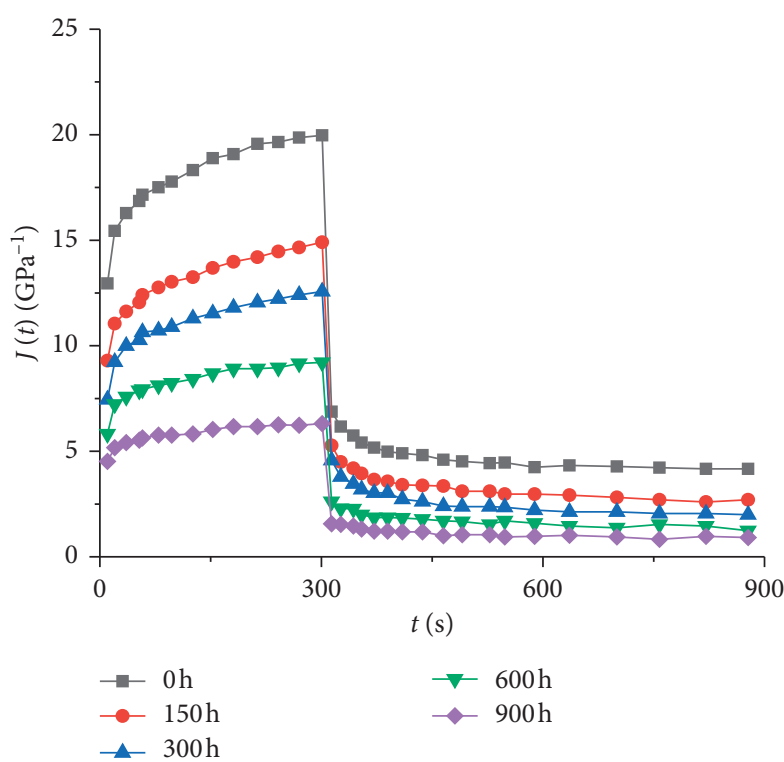

(c)

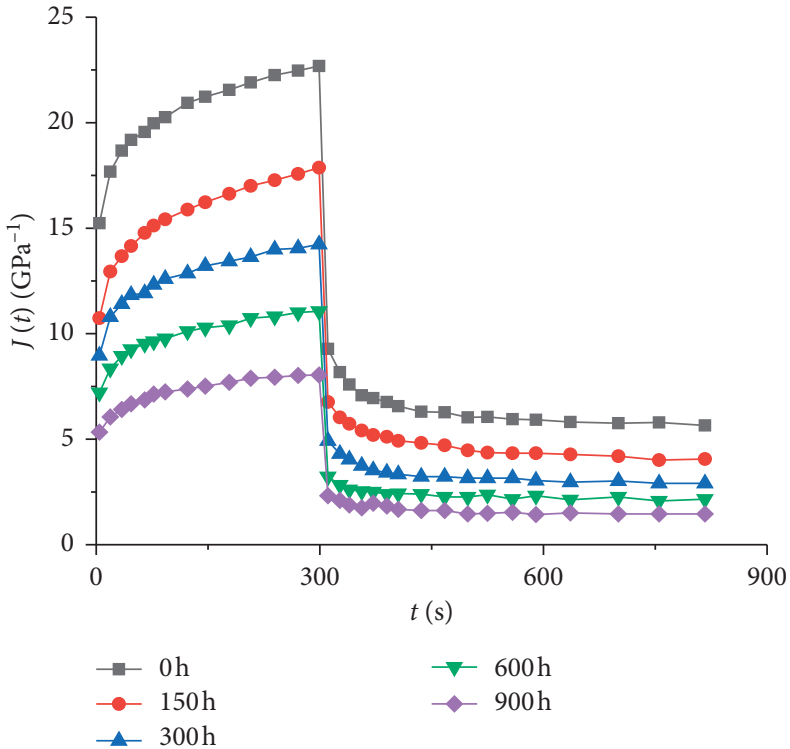

(d)

Figure 7: Creep compliance curve of creep recovery test of CA cement with different aging times. (a) A/C = 0.6. (b) A/C =0.8. (c) A/C=1.0. (d) $\mathrm{A} / \mathrm{C}=1.2$

strain decreases, indicating that the temperature rises and the deformation recovery ability gradually weakens. The above analysis shows that, as the temperature increases, the proportion of recoverable deformation of CA composite cement decreases, the proportion of nonrecoverable deformation of viscosity and plasticity increases, and the ability of CA composite cement to resist deformation and deformation recovery ability decreases. This is consistent with the influence law of stress level. In the material composition of CA composite cement, the temperature sensitivity of asphalt is greater while the temperature sensitivity of cement is lower. When the temperature rises, the asphalt material softens and fluidity increases, resulting in a gradual increase in the proportion of viscoplastic deformation. At the same time, as the temperature increases, the elastic properties of CA composite cement decrease, resulting in a gradual decrease in the ratio of elasticity and viscoelastic deformation.

3.4. Influence of $A / C$ on Viscoelastic-Plastic Mechanical Properties. The viscoelastic and plastic mechanical properties of CA composite cement are mainly determined by the interaction of cement hydration products, asphalt, and asphalt and cement hydration products. Among them, cement hydration products mainly affect its elastic properties, and asphalt mainly affects its viscosity properties. As well as plastic properties, the interaction of asphalt and cement hydration products affects its delayed elastic properties. Therefore, it is necessary to analyze the influence of the composition material ratio of CA composite cement on its viscoelastic-plastic mechanical properties. The changes of parameters $J_{K}(600) / J(600), J_{K}(600) / J_{H}(600)$, and $J_{1}(600) / J(0)$ with A/C are shown in Figures 13-15. It can be seen from subfigure (a) that, under the corresponding force level condition, $J_{K}(600) / J(600)$ increases with the increase of $\mathrm{A} / \mathrm{C}$; that is, the ratio of viscoplastic strain to total strain increases, indicating that with $\mathrm{A} / \mathrm{C}$ increases, the proportion of viscoplastic deformation of the specimen increases; as can be seen from subfigure (b), $J_{K}(600) / J_{H}(600)$ increases with the increase of $\mathrm{A} / \mathrm{C}$, and the strain and plasticity can be restored. The strain ratio gradually decreases, indicating that as $\mathrm{A} / \mathrm{C}$ increases, the deformation recovery capacity gradually decreases; as can be seen from subfigure $(c), J_{1}(600) / J(0)$ shows a decreasing trend as A/C increases; that is, the ratio of elastic strain to elastic-plastic strain decreases, indicating that $\mathrm{A} / \mathrm{C}$ increases and elastic deformation recovery capacity decreases.

The above analysis shows that, with the increase of the $\mathrm{CA}$ composite cement $\mathrm{A} / \mathrm{C}$, that is, the increase in the amount of asphalt, the elastic performance of the CA composite cement weakens and the proportion of viscous deformation and plastic deformation increases. The viscous component in the CA composite cement increases with the proportion of elastic components increasing. The elastic performance of CA composite cement mainly depends on the hydration products of cement, while the viscoplastic performance mainly depends on asphalt. Therefore, as the amount of asphalt increases, that is, the greater the $\mathrm{A} / \mathrm{C}$, the elastic performance of CA composite cement decreases and flows. The deformation ability is enhanced, and the material's ability to resist deformation and deformation recovery is weakened. In addition, in the law of $J_{1}(600) / J(0)$ changing with $\mathrm{A} / \mathrm{C}$, when $\mathrm{A} / \mathrm{C}=0.9$, there is a fluctuation, which is mainly caused by the microstructure composition and material ratio of $\mathrm{CA}$ composite cement. Performance changes are related. 


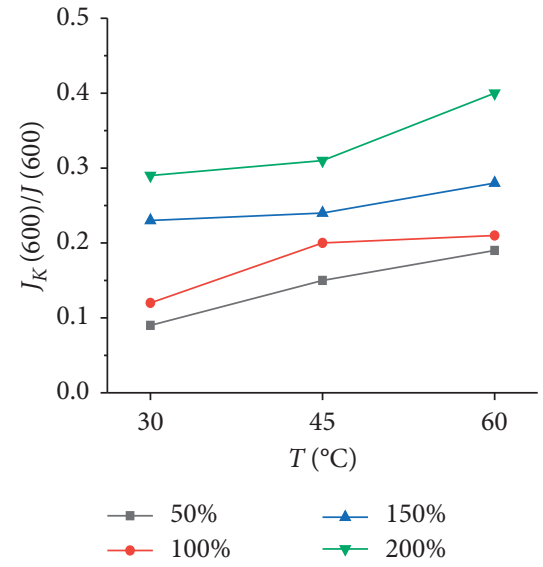

(a)

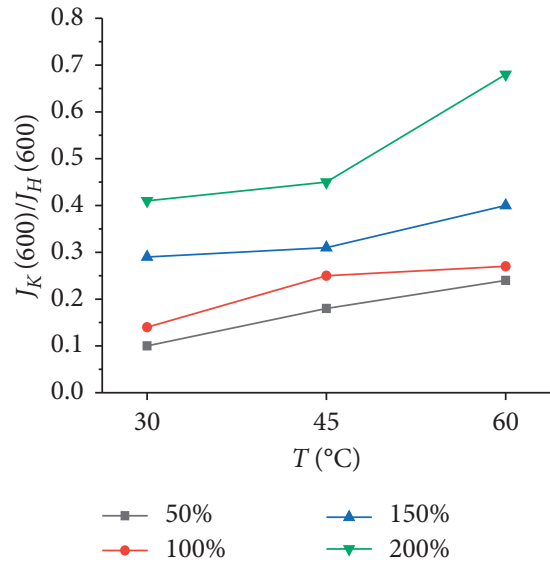

(b)

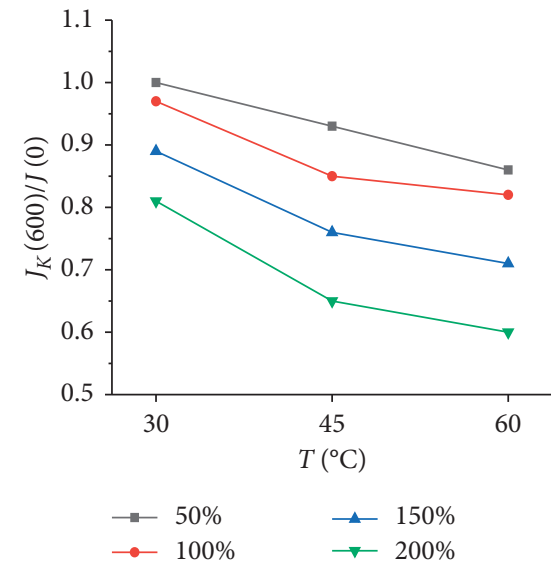

(c)

Figure 8: A/C $=0.3$ creep compliance data curve. (a) $J_{K}(600) / J(600)$. (b) $J_{K}(600) / J_{H}(600)$. (c) $J_{1}(600) / J(0)$.

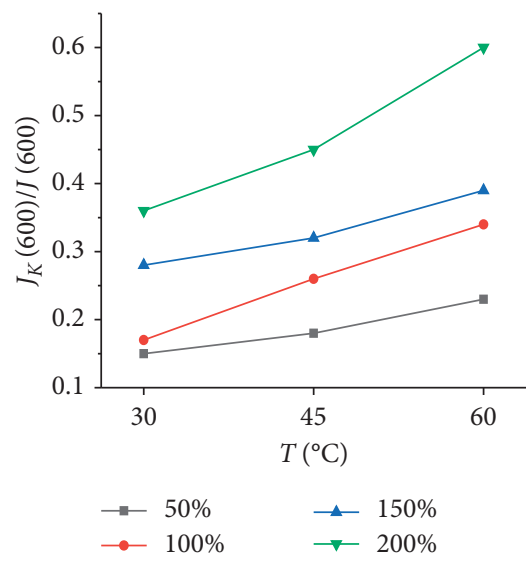

(a)

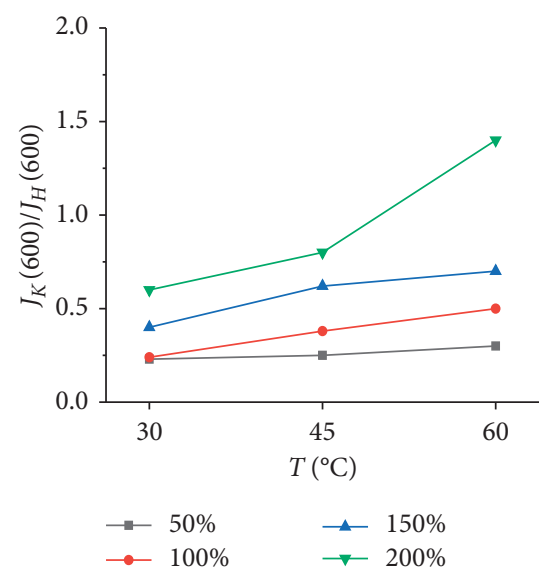

(b)

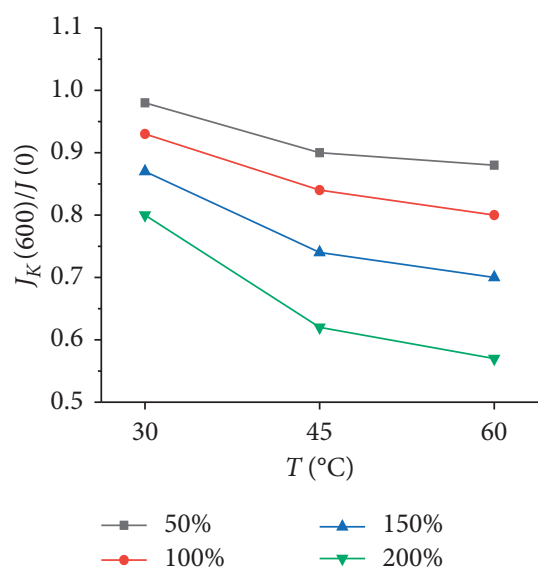

(c)

Figure 9: A/C $=0.6$ creep compliance data curve. (a) $J_{K}(600) / J(600)$. (b) $J_{K}(600) / J_{H}(600)$. (c) $J_{1}(600) / J(0)$.

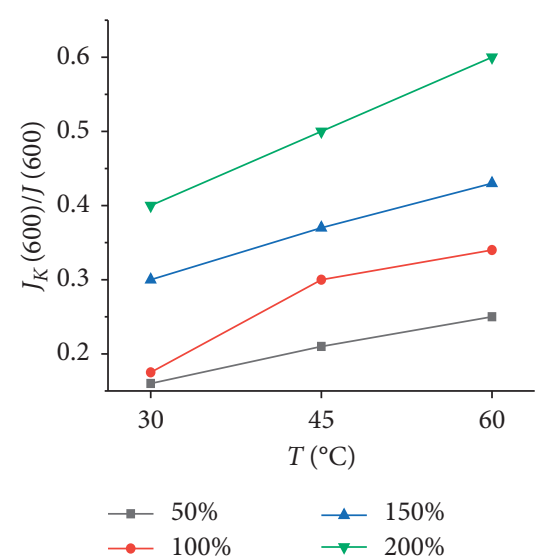

(a)

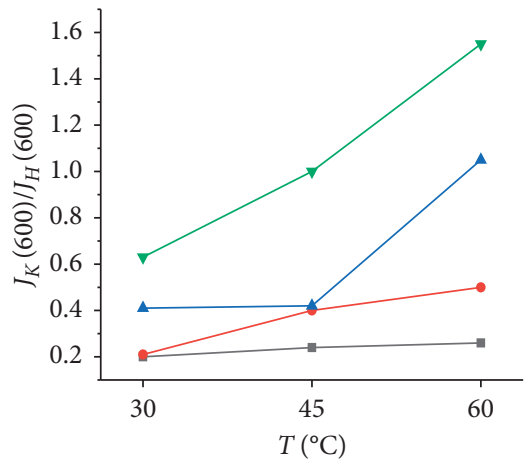

$\rightarrow 50 \% \rightarrow 150 \%$

(b)

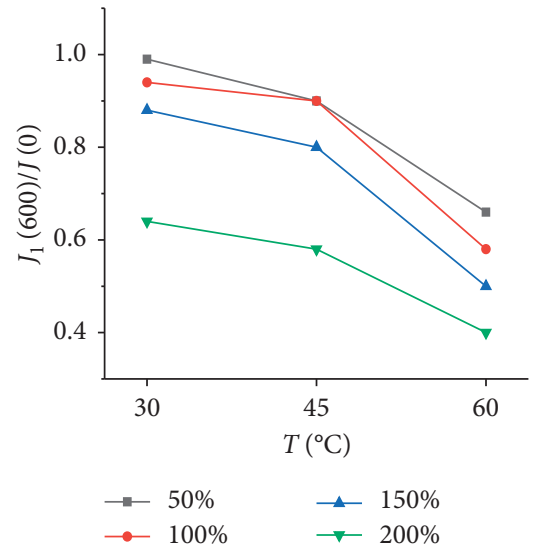

(c)

Figure 10: $\mathrm{A} / \mathrm{C}=0.9$ creep compliance data curve. (a) $J_{K}(600) / J(600)$. (b) $J_{K}(600) / J_{H}(600)$. (c) $J_{1}(600) / J(0)$. 


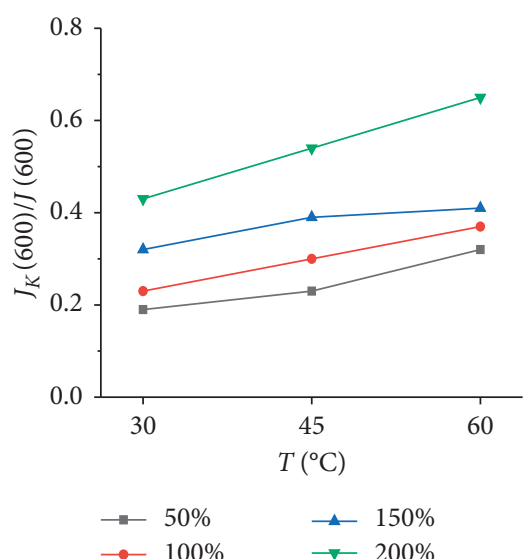

(a)

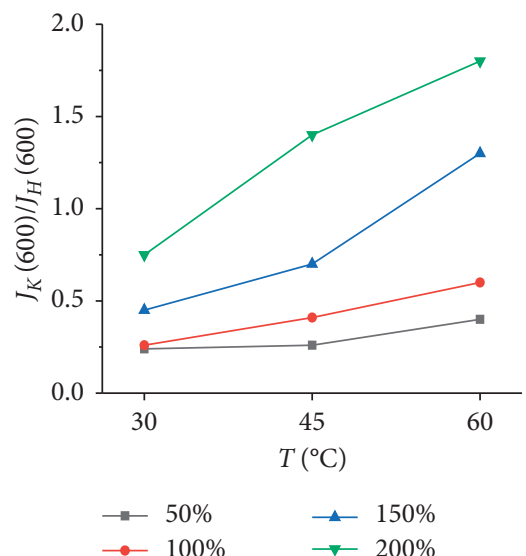

(b)

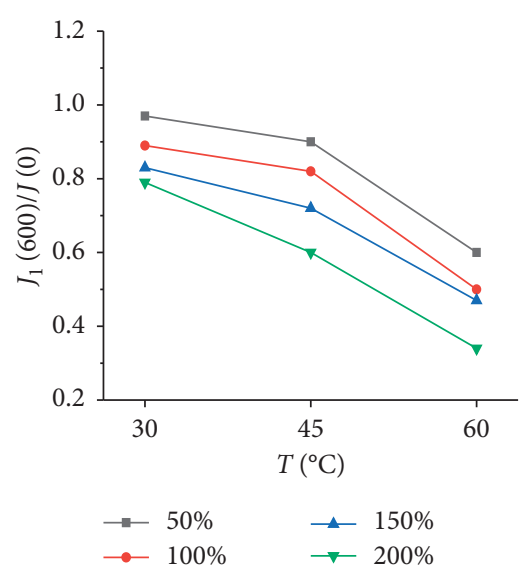

(c)

Figure 11: A/C=1.2 creep compliance data curve. (a) $J_{K}(600) / J(600)$. (b) $J_{K}(600) / J_{H}(600)$. (c) $J_{1}(600) / J(0)$.

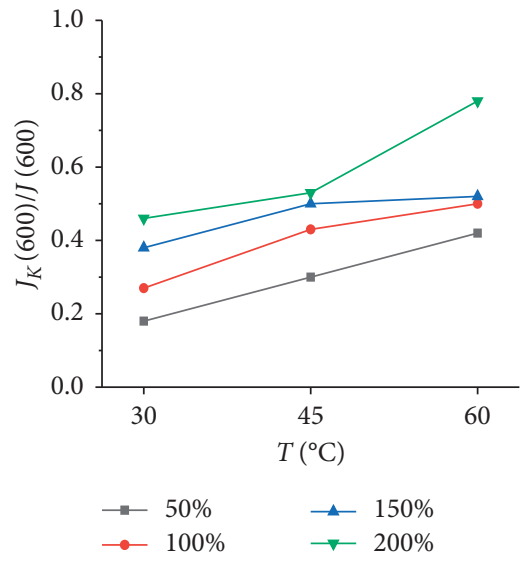

(a)

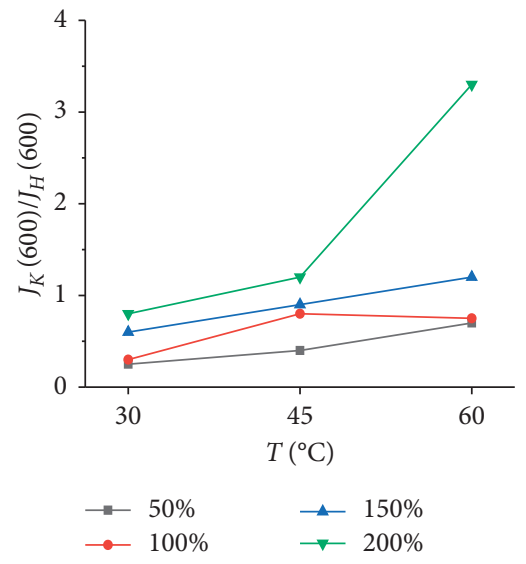

(b)

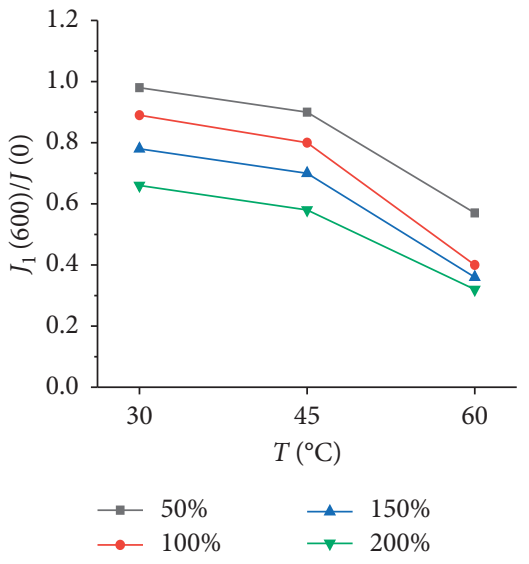

(c)

FIGURE 12: A/C $=1.5$ creep compliance data curve. (a) $J_{K}(600) / J(600)$. (b) $J_{K}(600) / J_{H}(600)$. (c) $J_{1}(600) / J(0)$.

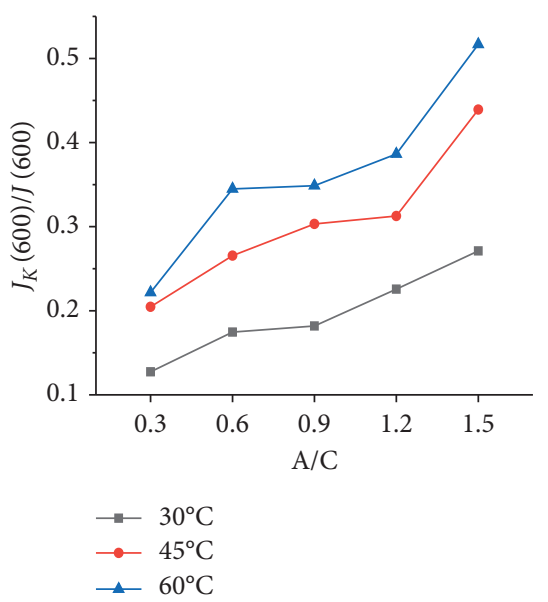

(a)

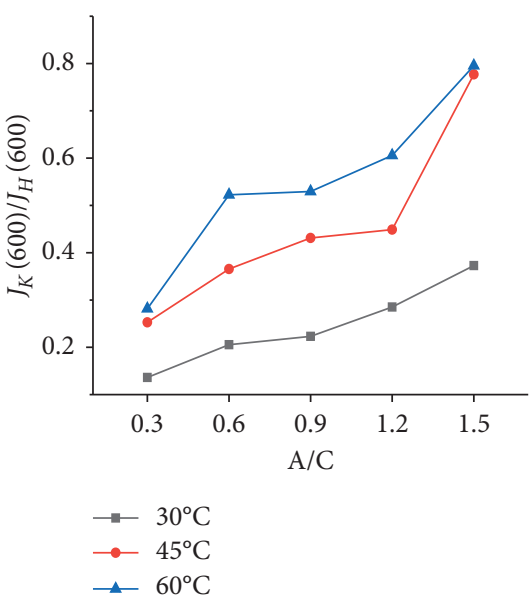

(b)

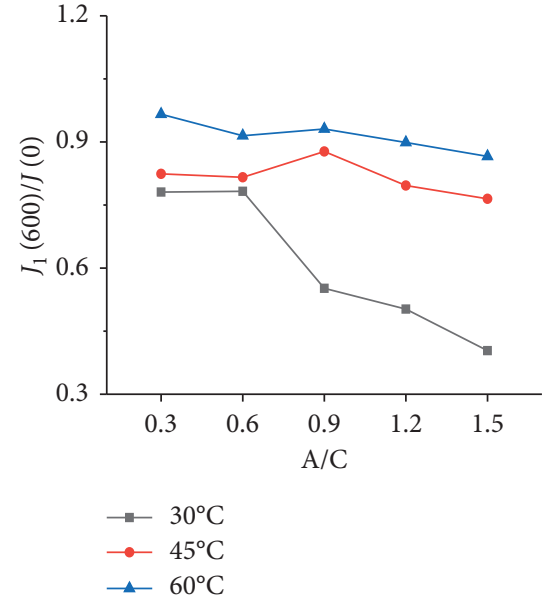

(c)

FIgURE 13: Creep compliance data curve at $100 \%$ stress level. (a) $J_{K}(600) / J(600)$. (b) $J_{K}(600) / J_{H}(600)$. (c) $J_{1}(600) / J(0)$. 


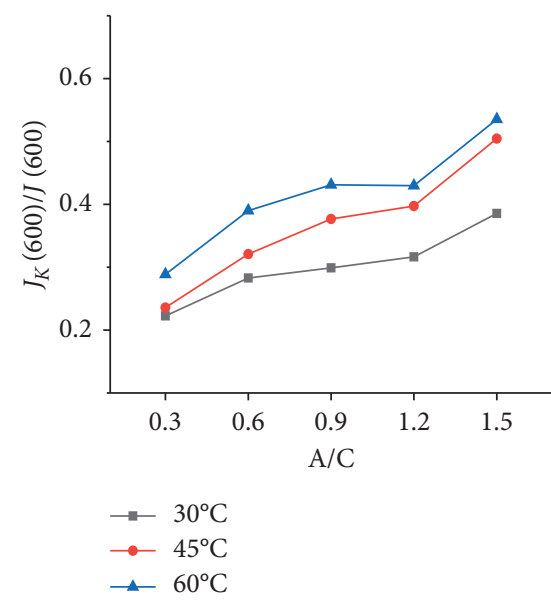

(a)

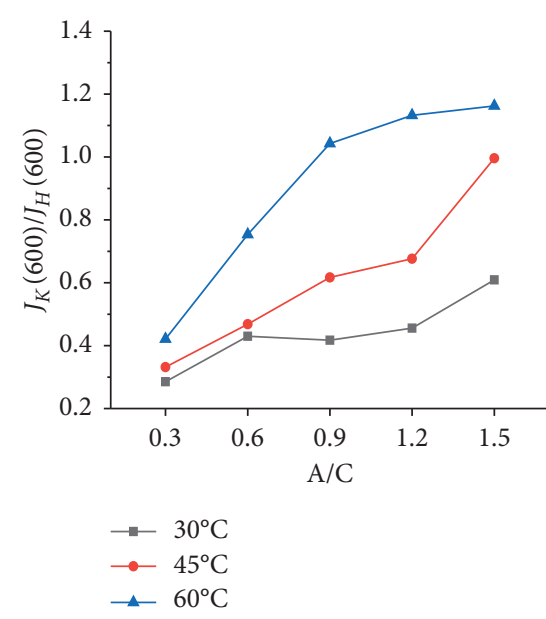

(b)

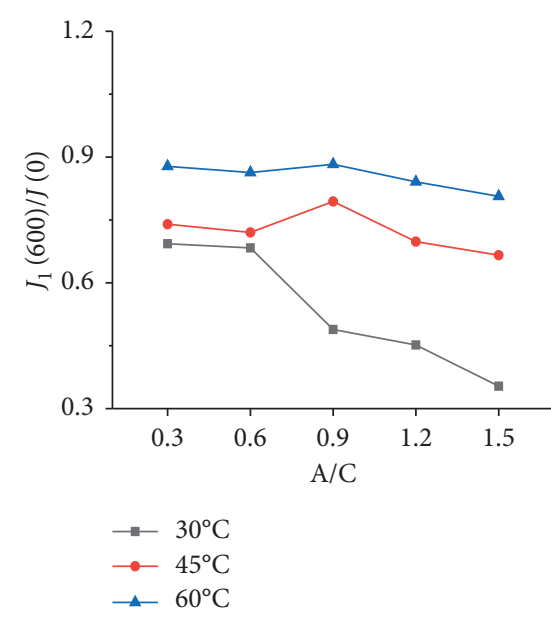

(c)

FIgURE 14: Creep compliance data curve at $150 \%$ stress level. (a) $J_{K}(600) / J(600)$. (b) $J_{K}(600) / J_{H}(600)$. (c) $J_{1}(600) / J(0)$.

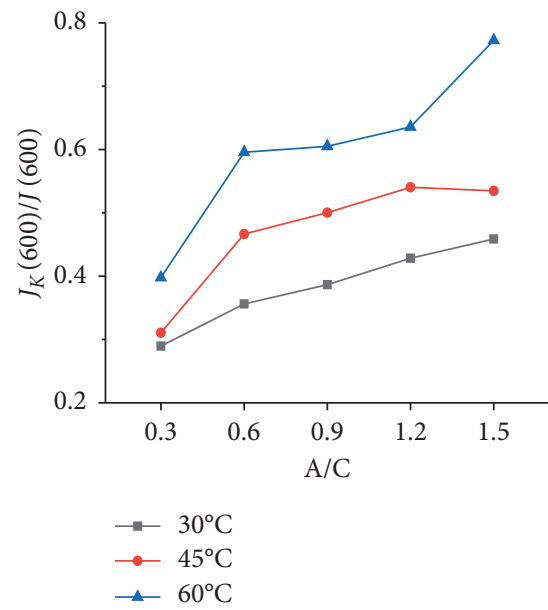

(a)

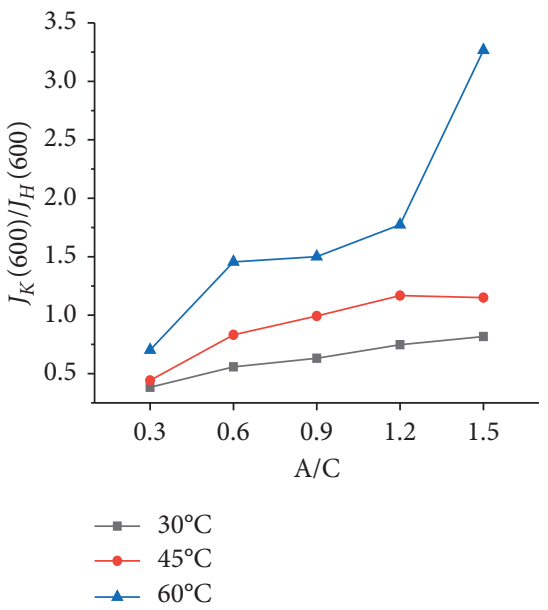

(b)

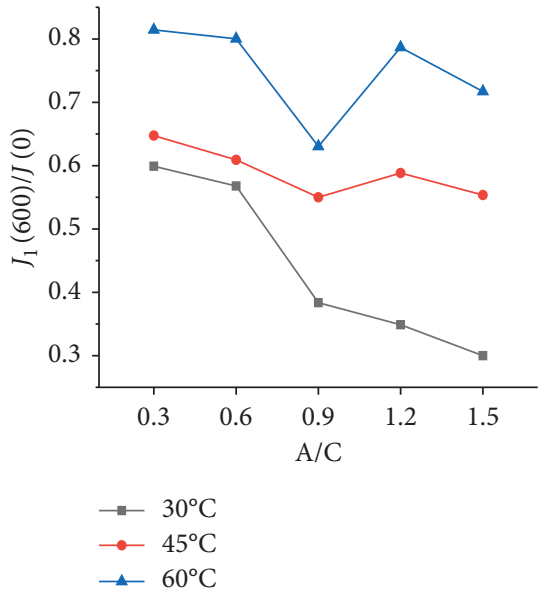

(c)

FIGURE 15: Creep compliance data curve at $200 \%$ stress level. (a) $J_{K}(600) / J(600)$. (b) $J_{K}(600) / J_{H}(600)$. (c) $J_{1}(600) / J(0)$.

In summary, it can be seen that the stress level, temperature, and $\mathrm{A} / \mathrm{C}$ have a greater impact on the viscoelasticplastic mechanical properties of CA composite cement. When the stress level is high, the material is prone to damage, and the greater the stress level, the greater the creep damage, resulting in a significant change in the material's viscoelastic and plastic mechanical properties; temperature and $\mathrm{A} / \mathrm{C}$ mainly affect the ratio of viscous and elastic components in the material relationship, and temperature and $\mathrm{A} / \mathrm{C}$ changes will lead to changes in the relative proportions of viscous components and elastic components in the material, leading to changes in the deformability of CA composite cement. With the increase of temperature and $\mathrm{A} / \mathrm{C}$, the ratio of viscoplastic deformation of CA composite cement increases, and the ability to resist deformation and the ability to recover from deformation are weakened.

\section{Conclusion}

In this paper, the creep and creep recovery tests of CA composite cement are carried out. Based on the results of creep and creep recovery tests, the creep and creep recovery characteristics of CA composite cement and the effects of aging on their creep properties are analyzed. The effects of temperature and material ratio on the viscoelastoplastic mechanical properties of CA composite cement are studied, and the conclusions are as follows:

(1) As the degree of aging increases, the creep compliance of CA cement decreases, the creep deformation ability decreases, the proportion of creep recovery deformation increases, the proportion of residual deformation decreases, and the deceleration creep and deceleration creep recovery stages tend to 
disappear, and the overall static mechanical properties of the material tend to be elastic.

(2) With the increase of temperature, the proportion of recoverable deformation of CA composite cement decreases, the proportion of nonrecoverable deformation of viscosity and plasticity increases, and the ability of CA composite cement to resist deformation and deformation recovery ability decreases.

(3) The elastic performance of CA composite cement mainly depends on the hydration products of cement, while the viscoplastic performance mainly depends on asphalt. Therefore, as the amount of asphalt increases, that is, the greater the $\mathrm{A} / \mathrm{C}$, the elastic performance of the CA composite cement decreases and increases the flow deformation ability, and the material resistance to deformation and deformation recovery ability is reduced.

\section{Data Availability}

No data were used to support this study.

\section{Conflicts of Interest}

The authors declare that they have no conflicts of interest.

\section{Acknowledgments}

This research was funded by the Science and Technology Project of Henan Department of Transportation (2020J-2-3) and Shaanxi Transportation Science and Technology Project (nos. 19-10K and 19-28K).

\section{References}

[1] R. Chang and H. Peiwen, "Rheological properties and aging mechanism of crumb rubber/ret modified asphalt before and after aging," Journal of Building Materials, vol. 6, no. 20, pp. 914-920, 2017.

[2] T. Wang, H. Jia, and H. Li, "Rheological properties of CRTs I cement emulsified asphalt mortar," Journal of Civil Engineering and Management, vol. 1, no. 35, pp. 48-53, 2018.

[3] H. Li, W. Wang, W. Li, A. Taoum, G. Zhao, and P. Guo, "Replacement of limestone with volcanic stone in asphalt mastic used for road pavement," Arabian Journal for Science and Engineering, vol. 44, no. 10, pp. 8629-8644, 2019.

[4] Y. Li, Y. Liu, Ji Lun et al., "Influence of aging on dynamic mechanical properties of cement emulsified asphalt binder," Journal of Composite Materials, vol. 7, no. 35, pp. 299-306, 2018.

[5] H. Li, G. Liu, B. Dong et al., "Research on the development and regeneration performance of asphalt rejuvenator based on the mixed waste engine oil and waste cooking oil," International Journal of Pavement Research and Technology, vol. 12, no. 3, pp. 336-346, 2019.

[6] X. Zhou, Y. Xie, K. Zheng et al., "Quality change and volume stability of cement emulsified asphalt mortar under dry wet cycle," Acta Silicate Sinica, vol. 7, no. 46, pp. 895-904, 2018.

[7] C. Zhang, X. Cao, S. Jiao et al., "Viscoelastic plastic compaction characteristics of cement emulsified asphalt mixture based on Bodner partom model," Acta Highway Sinica, vol. 7, no. 32, 2019.

[8] F. Yang, H. Li, G. Zhao et al., "Mechanical performance and durability evaluation of sandstone concrete," Advances in Materials Science and Engineering, vol. 2020, Article ID 2417496, 2020.

[9] X.. Bao, "Study on the influence of emulsified asphalt content on the performance of super early strength CAEM," Highway, vol. 3, no. 64, pp. 246-250, 2019.

[10] H. Li, B. Dong, W. Wang et al., "Effect of waste engine oil and waste cooking oil on performance improvement of aged asphalt," Applied Sciences, vol. 9, no. 9, 2019.

[11] J. Ouyang, H. Li, and B. Han, "The rheological properties and mechanisms of cement asphalt emulsion paste with different charge types of emulsion," Construction and Building Materials, vol. 147, pp. 566-575, 2017.

[12] H. Gengren, W. Huang, J. Yuan et al., "Effect of aging on chemical and rheological properties of SBS modified asphalt with different compositions," Construction and Building Materials, vol. 156, pp. 902-910, 2017.

[13] H. Li, W. Li, A. A. Temitope et al., "Analysis of the influence of production method, crumb rubber content and stabilizer on the performance of asphalt rubber," Applied Sciences, vol. 10, no. $16,2020$.

[14] P. Li, Z. Ding, L. x. Ma, and Z. g. Feng, "Analysis of viscous flow properties of asphalt in aging process," Construction and Building Materials, vol. 124, pp. 631-638, 2016.

[15] A. Rasouli, A. Kavussi, M. J. Qazizadeh, and A. H. Taghikhani, "Evaluating the effect of laboratory aging on fatigue behavior of asphalt mixtures containing hydrated lime," Construction and Building Materials, vol. 164, pp. 655-662, 2018.

[16] A. Chen, G. Liu, Y. Zhao, J. Li, Y. Pan, and J. Zhou, "Research on the aging and rejuvenation mechanisms of asphalt using atomic force microscopy," Construction and Building Materials, vol. 167, pp. 177-184, 2018.

[17] Y. Ji, Study on Cement Emulsified Asphalt Mortar for Ballastless Track of High Speed Railway, Chang'an University, Xi'an, China, 2011.

[18] H. Song, Y. Xie, and G. long, "Research progress of cement emulsified asphalt mortar," Materials Guide, vol. 5, no. 32, pp. 836-846, 2018.

[19] Y. F. Fu, Y. L. Wong, C. S. Poon et al., "Experimental study of micro/macro crack development and stress-strain relations of cement-based composite materials at elevated temperatures," Cement and Concrete Research, vol. 5, no. 34, pp. 789-797, 2004.

[20] F. de A. L. B. Lucas, S. F. Jorge Luis, J. B. Soares et al., “Agingeffect incorporation into the fatigue-damage modeling of asphalt mixtures using the S-VECD model," Journal of Materials in Civil Engineering, vol. 12, no. 28, 2016.

[21] M. Saber, W. Sun, and T. H. Hyde, "Numerical study of the effects of crack location on creep crack growth in weldment," Engineering Fracture Mechanics, vol. 154, pp. 72-82, 2016.

[22] H. Xu and P. Wang, "Effects of strain rate and stress level on dynamic compressive property of CA mortar," Journal of Building Materials, vol. 6, no. 18, pp. 1084-1088, 2015.

[23] H. Li, B. Dong, D. Zhao, P. Guo, and J. Zhang, "Physical, rheological and stability properties of desulfurized rubber asphalt and crumb rubber asphalt," Arabian Journal for Science and Engineering, vol. 44, no. 5, pp. 5043-5056, 2019.

[24] H. song, X. Zeng, Y. Xie et al., "Creep characteristics of cement emulsified asphalt mortar under long-term load," Journal of Building Materials, vol. 2, no. 23, pp. 271-278, 2020. 
[25] D. S. Seo and H. B. Choi, "Effects of the old cement mortar attached to the recycled aggregate surface on the bond characteristics between aggregate and cement mortar," Construction and Building Materials, vol. 59, pp. 72-77, 2014. 